\title{
Analysis of $\mathrm{MSH} 2$ Loss of Heterozygosity, Expression, and IVS10+12G>A Polymorphism in Sporadic Colon Cancer
}

\author{
TAMARA CACEV ${ }^{1}$, EMILIJA ZAPLETAL ${ }^{1}$, VESNA MUSANI ${ }^{1}$, IVANA RAKO $^{1}$, \\ BOZO LONCAR $^{2}$, GORANA ARALICA ${ }^{2,3}$ and SANJA KAPITANOVIC ${ }^{1}$ \\ ${ }^{1}$ Division of Molecular Medicine, Rudjer Boskovic Institute, Zagreb, Croatia; \\ ${ }^{2}$ Clinical Hospital Dubrava, Zagreb, Croatia; \\ ${ }^{3}$ School of Medicine, University of Zagreb, Zagreb, Croatia
}

\begin{abstract}
Background: mutS homolog 2 (MSH2) deficiency may be involved in the development of microsatellite instability found in certain sporadic colorectal tumors. In addition to mutations or loss of heterozygosity resulting in complete loss of MSH2 function, polymorphisms affecting MSH2 expression have been also identified. Therefore, the aim of this study was to examine MSH2 status in sporadic colon cancer. Materials and Methods: MSH2 status was examined at the DNA, RNA and protein levels through loss of heterozygosity $(\mathrm{LOH})$ analysis, quantitative real-time PCR and immunohistochemistry. MSH2 IVS10 $+12 A>G$ polymorphism was examined by real-time single nucleotide polymorphism genotyping. Results: MSH2 LOH was more frequent in tumors larger than $5 \mathrm{~cm}(p=0.032), m R N A$ expression was also significantly lower and the same expression pattern was present in the corresponding normal mucosa of the same patient ( $p=0.013$ and $p=0.008$, respectively). No association was found between IVS10+12A>G polymorphism and susceptibility to sporadic colon cancer. Conclusion: Altered MSH2 expression detected in sporadic colon tumors pointing to its role in colorectal tumorigenesis without a hereditary component.
\end{abstract}

Colorectal cancer arises as a result of the progressive accumulation of genetic and epigenetic alterations associated with the transformation of normal colonic epithelium to colon adenocarcinoma (1). More than three decades of intensive research have led to recognition of two major pathways

Correspondence to: Tamara Čačev, Ph.D. Laboratory for Personalized Medicine, Division of Molecular Medicine, Rudjer Boskovic Institute, Bijenicka c. 54, HR-10000 Zagreb, Croatia. Tel: +385 14571383, Fax: +385 14561010, e-mail: tcacev@irb.hr

Key Words: MSH2 gene, LOH, mRNA expression, immunohistochemistry, IVS10+12G>A, sporadic colon cancer. involved in colorectal carcinogenesis, the suppressor and the mutator pathway, with different clinical behaviors and responses to chemotherapy (2).

The suppressor pathway follows the canonical adenomacarcinoma sequence and is characterized by progressive accumulation of somatic mutations in oncogenes (e.g. Kirsten rat sarcoma viral oncogene homolog, KRAS) and tumor suppressor genes (e.g. adenomatous polyposis coli, $A P C$; tumor protein $p 53, T P 53$; and deleted in colorectal carcinoma/SMAD family member 4, DCC/SMAD4). In addition, chromosomal instability is frequently found in colon cancer arising through this pathway, as opposed to the mutator pathway, whose distinctive feature is microsatellite instability (MSI) $(3,4)$. MSI occurs in $15-20 \%$ of sporadic human colorectal tumors and in $>95 \%$ of colon cancer arising in patients with Lynch syndrome (5). Microsatellite unstable colorectal cancer is associated with the accumulation of numerous replication errors, mainly small insertions and deletions in repetitive sequences (microsatellites) caused by inactivation of human mismatch repair (MMR) system. There are six crucial MMR genes in humans: mutL homolog 1 (MLH1), mutS homolog 2 (MSH2), mutS homolog 3 (MSH3), mutS homolog 6 (MSH6), PMS1 homolog 1 (PMS1) and PMS1 homolog 2 (PMS2) (6). Heterodimers consisting of $\mathrm{MSH} 2$ and $\mathrm{MSH} 3$ are involved in the recognition of large insertion-deletion loops in DNA. Additionally, a complex consisting of MSH2 and MSH6 scans newly-synthesized DNA for mispaired bases or shorter deletion/insertion loops (7).

It is well established that MSH2 deficiency leads to increased accumulation of base substitutions and frameshifts, enhanced recombination between homologous but nonidentical DNA sequences, and tolerance to cytotoxic effects of methylating agents (8). In addition to MSH2 deficiency caused by mutations or the complete loss of the $\mathrm{MSH} 2$ gene, the expression level of MSH2 is also important for the adequate fulfillment of MSH2 action. As MSH2 is one of the key 
enzymes in the MMR system, several studies have tried to establish a possible correlation between the MSH2 expression level and response of patients with colorectal to therapy and survival (9).

In addition to germline mutations, many common polymorphisms in MMR genes have been identified and it has been proposed that they could lead to inter-individual differences in DNA repair function, possibly through their influence on alternative splicing and, in consequence, variation in expression level of splicing variants with different DNA repair capacity (10).

Therefore, taking these findings into account and in an effort to elucidate the role of the $M S H 2$ gene in tumorigenesis of sporadic colon cancer, we examined its status at DNA, mRNA and protein levels and its association with patients' clinicopathological characteristics and survival.

\section{Materials and Methods}

Patients and controls. In our study, the population control group consisted of 200 unrelated healthy volunteers and a group of 200 patients with sporadic colon cancer. Specimens (tumor and adjacent normal colon tissue) from patients with sporadic colon cancer and blood samples of controls used in our study were obtained from the Croatian Tumor Bank at the Ruđer Bošković Institute, Zagreb, Croatia (11). During the collection of samples from cases and controls, demographic characteristics, age, sex and family history of cancer were recorded. The case group consisted of patients with sporadic colon cancer, with negative family history of hereditary cancer. All specimens were obtained during routine surgery of patients with colon adenocarcinoma. None of the patients underwent preoperative irradiation or chemotherapy. Diagnoses were established by standard diagnostic procedures and confirmed histopathologically. Fresh samples of resected colon carcinoma were snap-frozen in liquid nitrogen and stored at $-80^{\circ} \mathrm{C}$ until further use for RNA and DNA extraction. Before use in the study, each specimen was verified by a histopathologist. All specimens were examined by routine hematoxylin and eosin staining. Patient DNA was extracted from histologically normal colon mucosa adjacent to adenocarcinoma (15 $\mathrm{cm}$ away from the tumor). DNA extraction was performed using proteinase $\mathrm{K}$ digestion and phenol-chloroform extraction. Control group DNA was extracted from blood samples of controls. Control for our study were randomly selected among unrelated volunteers without a history of tumors or other serious illnesses. Ethics Committee approval was obtained (on 20th Feb 2006 and 30th Oct 2014) and written consent was provided by all participants.

Loss of heterozygosity ( $\mathrm{LOH}$ ) analysis at the MSH2 gene locus. For $\mathrm{LOH}$ analysis at the $\mathrm{MSH} 2$ gene locus, two sets of primers for two intragenic polymorphic microsatellite markers, D2S123 and D2S378, were used. Sequences of specific oligonucleotides used were: D2S123A: 5'-AAA CAG GAT GCC TGC CTT TA-3' and D2S123B: 5'-GGA CTT TCC ACC TAT GGG AC-3' for D2S123; and D2S378A: 5'-CTC CCT CTC AGG CTA AAC CT-3' and D2S378B: 5'-GAA ATA TGT GGA GGT TCA GAG-3' for D2S378. Genomic DNA (100 ng) was used as a template in a reaction volume of $25 \mu \mathrm{l}$ containing 5 pmol of each primer, $50 \mu \mathrm{M}$ of each dNTP, and $1 \mathrm{U}$ Taq Gold DNA polymerase (Applied Biosystems, Foster City, CA, USA).
Polymerase chain reaction (PCR) reactions were carried out in an Applied Biosystems GeneAmp PCR System 2400 for 30 cycles. Annealing temperatures for each primer set were optimized in pilot studies before processing analytical samples.

$\mathrm{LOH}$ analysis was performed by non-denaturing polyacrylamide electrophoresis. For this analysis, $5 \mu \mathrm{l}$ of PCR product were mixed with $3 \mu \mathrm{l}$ of loading buffer and loaded onto $1 \mathrm{~mm}$ thick, $35 \times 30 \mathrm{~cm}$, $10 \%$ nondenaturing polyacrylamide gel. Electrophoresis was performed in 1x Tris/Borate/EDTA buffer for $16 \mathrm{~h}$ at $10 \mathrm{~V} / \mathrm{cm}$, at room temperature. The gels were silver stained. $\mathrm{LOH}$ was defined by visible change in allele:allele ratio in tumors compared with their matched normal tissue. Allelic deletion of the MSH2 gene was judged by positive $\mathrm{LOH}$ at either of the two sites.

MSI analysis. For MSI analysis, paired tumor and normal DNA was used and MSI was examined at five loci according to the consensus of the National Cancer Institute Workshop on Microsatellite Instability for Colorectal Cancer Detection (12). Primer sequences used were as follows: D2S123: forward (F): 5'-AAACAGGATGC CTGCCTTTA-3' and reverse (R): 5'-GGACTTTCCACCTATGG GAC-3'; D5S346 F: 5'-ACTCACTCTAGTGATAAATCGGG-3' and R: 5'-AGCAGATAAGACAGTATTACTAGTT-3'; D17S250 F: 5'GGAAGAATCAAATAGACAAT-3' and R: 5'-GCTGGCCATATAT ATATTTAAACC-3'; BAT-25a F: 5'-TCGCCTCCAAGAATGTAA GT-3' and R: 5'-TCTGCATTTTAACTATGGCTC-3'; BAT-26 F: 5'CTGCGGTAATCAAGTTTTTAG-3' and R: 5'-AACCATTCAACA TTTTTAACCC-3'.

All forward primers were fluorescently labelled. Genomic DNA (100 ng) was used as a template in a reaction volume of $25 \mu \mathrm{l}$ containing 5 pmol of each primer, $50 \mu \mathrm{M}$ of each dNTP, and $1 \mathrm{U}$ Taq Gold DNA polymerase (Applied Biosystems). PCR reactions were carried out in an Applied Biosystems GeneAmp PCR System 2400 for 25 cycles. Annealing temperatures for each primer set were optimized in pilot studies before processing analytical samples. MSI analysis was performed using ABIPRISM 310 genetic analyzer, with GeneScan software (Applied Biosystems). MSI was defined as either alteration in the length of the amplified PCR product (ladder pattern) or as a new band above or below that expected for the allele. The sample was denoted as MSI high (MSI-H) if two or more of the markers demonstrated instability. The sample was denoted as having low MSI (MSI-L) if the MSI was detected only in one of the analyzed markers. The sample was considered as microsatellite stable (MSS) where no instability was detected in any of the analyzed markers (12).

MSH2 IVS10+12G>A polymorphism analysis. Real-time PCR-single nucleotide polymorphism (SNP) analysis of the $M S H 2$ IVS10+12G $>A$ (rs3732183) polymorphism was performed using an ABI PRISM 7000 SDS (Applied Biosystems) and pre-developed TaqMan SNP genotyping assay C 27470648_10 (Applied Biosystems). PCR reaction was carried out according to the manufacturer's protocol. Six samples representing three possible SNP genotypes for each SNP were run in parallel with tested DNA samples.

RNA extraction and reverse transcription. Total RNA was extracted from 50 pairs of resected colon carcinoma and corresponding normal tissues using Trizol reagent (Invitrogen, Carlsbad, CA, USA) and 10 $\mu \mathrm{g}$ of RNA were used for reverse transcription (High-Capacity cDNA Archive Kit; Applied Biosystems) according to the manufacturer's protocols. The number of tumor samples analyzed was dependent upon sufficient RNA quality for real-time RT-PCR analysis. 
Real-time RT-PCR analysis of MSH2 mRNA expression. Real-time RT-PCR analysis for $M S H 2$ and ribosomal protein lateral stalk subunit $\mathrm{PO}(R P L P 0)$ (endogenous control gene) was performed using an $\mathrm{ABI}$ PRISM 7000 SDS and pre-developed TaqMan assay reagents, C11804028_10 (MSH2) and Hs99999902_m1 (RPLPO) (all Applied Biosystems). PCR reaction was carried out according to the manufacturer's protocol. Results are shown as $\Delta \mathrm{Ct}$ values which is the difference in cycle number required to raise the amount of PCR product above the threshold level; $\Delta \mathrm{Ct}$ is therefore inversely proportional to the amount of mRNA (13).

Immunohistochemical analysis of $\mathrm{MSH} 2$ protein expression. Immunohistochemical analysis of MSH2 protein expression was performed on formalin-fixed, paraffin-embedded tissue. Expression of MSH2 in 73 samples of sporadic colon cancer was analyzed using mouse monoclonal antibody for MSH2 (Ab-2; Calbiochem, Cambridge, MA, USA). Paraffin-embedded tissue sections of normal human colon stained with MSH2 antibody served as positive control. Negative controls were performed by omission of the primary antibody.

After deparaffinization in xylene, slides were rehydrated in ethanol and washed in phosphate-buffered saline $(3 \times 3 \mathrm{~min})$. The endogenous peroxidase activity was quenched by $15 \mathrm{~min}$ incubation in methanol with 3\% hydrogen peroxide (Sigma Chemical Co., Munich, Germany). Non-specific binding was blocked by applying DAKO ${ }^{\circledR}$ Protein Block Serum-Free (DAKO, Glostrup, Denmark) in a humidity chamber for $10 \mathrm{~min}$ at room temperature. Slides were blotted, and the primary mouse monoclonal antibody at $5 \mu \mathrm{g} / \mathrm{ml}$ was applied overnight at $4{ }^{\circ} \mathrm{C}$. Slides were then washed three times in phosphate-buffered saline (PBS). DAKO EnVision ${ }^{\mathrm{TM}}+$ System, HRP (DAB) (DAKO) was used for visualization of positive reaction according to the manufacturer's instructions. The slides were counterstained with hematoxylin for $30 \mathrm{~s}$, dehydrated and mounted in Canada balsam. Each slide was evaluated for the entire tumor area. The presence of brown staining was an indication of a positive immunohistochemical reaction.

Statistical analysis. Correlations between the MSH2 LOH status (or MSH2 immunostaining) and clinicopathological characteristics were explored from contingency tables. Tables were analyzed using the chisquare test or Fisher's exact test. Correlations were considered significant when the two tailed $p$-value was less than 0.05 . The Hardy-Weinberg equation was used to determine whether the proportion of each genotype obtained was in agreement with expected values calculated from allelic frequencies. Allelic and genotypic frequencies were compared between patient and control groups by chi-square test. A chi-square $p$-value of less than 0.05 was considered statistically significant. Logistic regression was used to estimate risk as odds ratio with $95 \%$ confidence intervals. Correlations of mRNA expression in normal and tumor tissue were analyzed with the Student's $t$-test; those for expression and clinicopathological characteristics were analyzed with Student's $t$-test or with the analysis of variance where appropriate. The probability of survival was calculated for the different subgroups by the Kaplan-Meier method. A $p$-value of less than 0.05 was considered statistically significant. All evaluations were performed using GraphPad Prism version 4.03 for Windows (GraphPad Software, San Diego, CA, USA).

\section{Results}

$\mathrm{LOH}$ at the MSH2 gene locus. DNA from 200 sporadic colorectal tumors was examined for $\mathrm{LOH}$ at the $\mathrm{MSH} 2$ gene locus using two intragenic variable number tandem repeat (VNTR) microsatellite markers: D2S123 and D2S378. In the LOH analysis, the DNA extracted from normal tissue showed one (homozygous) or two (heterozygous) bands at the specific VNTR locus. MSH2 LOH was demonstrated when the tumor DNA from heterozygous (informative) patients showed loss of one of these two bands (Figure 1).

At the D2S123 locus, 132 out of 200 patients were heterozygous $(66.0 \%)$ and 13 out of $132(9.8 \%)$ demonstrated LOH. At the D2S378 locus, 152 out of 200 patients were heterozygous $(76.0 \%)$ and 15 out of $152(9.8 \%)$ demonstrated LOH. Using these two polymorphic markers, the total heterozygosity was $90.5 \%$ (181 out of 200 samples tested) and in 24 out of 181 heterozygous tumors $(13.3 \%) \mathrm{LOH}$ was detected.

MSH2 LOH, clinicopathological characteristics and patient survival. The results of $\mathrm{LOH}$ analysis were correlated to clinicopathological features of patients and their tumors (age, sex, tumor size, tumor grade and Dukes' stage) (Table I). $M S H 2 \mathrm{LOH}$ was significantly more frequent in tumors larger than $5 \mathrm{~cm}$ in diameter than in smaller ones $(p=0.032)$ (Table I). A trend was observed for positive correlation between MSH2 LOH and histological grade (differentiation) of tumors: as the tumors were less differentiated, $\mathrm{LOH}$ was more frequent, however, this trend was not statistically significant $(p=0.188)$ (Table I). In addition, MSH2 LOH was more frequent in tumors classified as Dukes' $\mathrm{C}$ (metastatic tumors) than in those classified as Dukes' A or B, however, this difference was not statistically significant $(p=0.162)$ (Table I). No association between $\mathrm{MSH} 2 \mathrm{LOH}$ and age or sex of patients included in the study was observed ( $p=0.833$ and $p=0.579$, respectively) (Table I). Finally, no association was observed between $\mathrm{MSH} 2 \mathrm{LOH}$ and patient survival.

MSI. In this study, we examined the incidence of MSI using the National Cancer Institute Bethesda panel of microsatellite markers in 200 patients with sporadic CRC and MSI was detected in 32/200 (16.0\%) of the analyzed samples. Of these MSI-positive tumors 15 were MSI-H and 17 were MSI-L. The remaining tumors were classified as MSS.

MSI was significantly more frequent in larger tumors ( $p=0.0019)$. Indeed, 20/76 (26.3\%) of tumors larger than $5 \mathrm{~cm}$ in diameter were found to be MSI-positive compared to only $11 / 116(9.5 \%)$ of smaller tumors. No statistically significant association between the MSI status and other clinicopathological characteristics of patients and their tumors, nor with patient survival were observed.

MSH2 IVS10+12G $>$ A polymorphism. The frequencies of $M S H 2$ IVS10+12G $>$ A polymorphism were analyzed in a group of patients with colon cancer in comparison to a group of control individuals. All SNP genotypic frequencies in both 


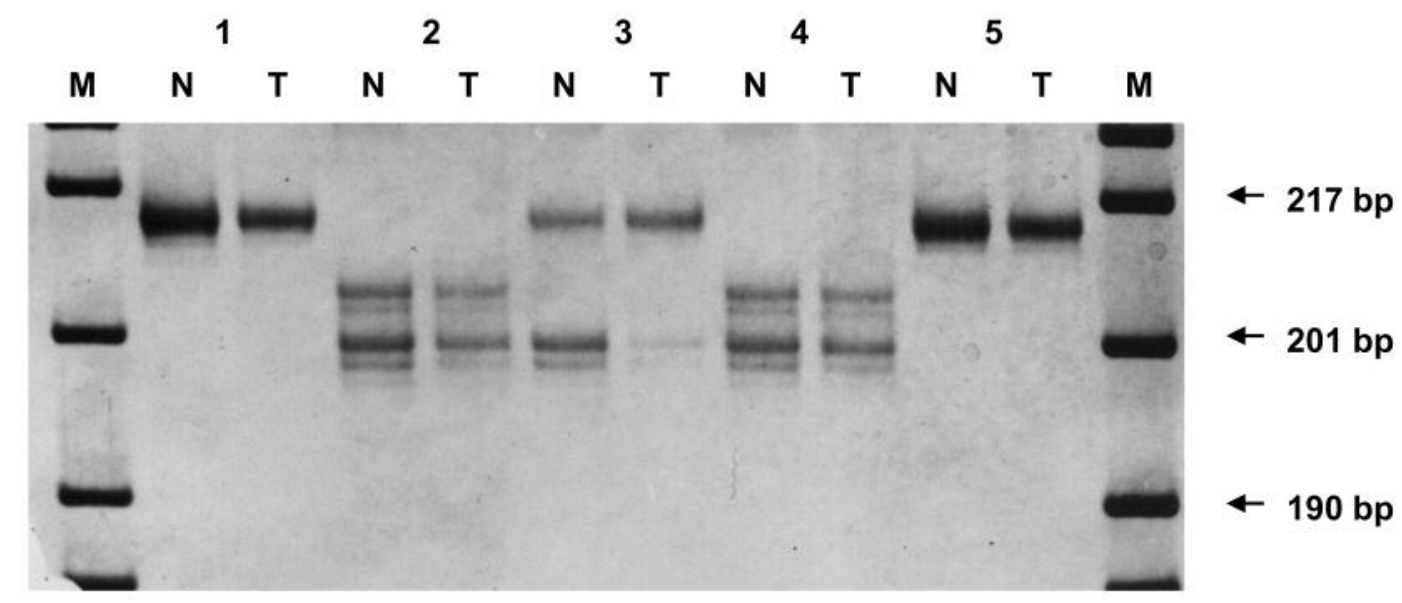

Figure 1. Loss of heterozygosity ( $\mathrm{LOH}$ ) analysis at the mutS homolog 2 (MSH2) gene microsatellite locus D2S123 in sporadic colon cancer. M, DNA marker pBR322/MspI digest; $N$, normal colonic tissue; $T$, tumoral tissue. 1, 5, homozygous sample (not informative); 2, 4, heterozygous sample without $\mathrm{LOH}$; 3, heterozygous sample with $\mathrm{LOH}$.

Table I. Clinicopathological features of 181 heterozygous patients with colon cancer stratified by mutS homolog 2 loss of heterozygosity (MSH2 LOH) status.

\begin{tabular}{|c|c|c|c|c|}
\hline \multirow[b]{2}{*}{ Characteristic } & \multirow[b]{2}{*}{$\begin{array}{c}\text { No. of } \\
\text { cases }\end{array}$} & \multicolumn{2}{|c|}{$\mathrm{MSH} 2$ gene $\mathrm{LOH}$} & \multirow[b]{2}{*}{$p$-Value } \\
\hline & & $\begin{array}{l}\text { Negative, } \\
\mathrm{n}(\%)\end{array}$ & $\begin{array}{l}\text { Positive, } \\
\text { n (\%) }\end{array}$ & \\
\hline \multicolumn{5}{|l|}{ Age } \\
\hline$<70$ years & 102 & $88(86.3)$ & $14(13.7)$ & \\
\hline$\geq 70$ years & 79 & $69(87.3)$ & $10(12.7)$ & 0.833 \\
\hline \multicolumn{5}{|l|}{ Gender } \\
\hline Male & 100 & $88(88.0)$ & $12(12.0)$ & \\
\hline Female & 81 & $69(85.2)$ & $12(14.8)$ & 0.579 \\
\hline \multicolumn{5}{|l|}{ Tumor size } \\
\hline$\leq 5 \mathrm{~cm}$ & 106 & $97(91.5)$ & $9(8.5)$ & \\
\hline$>5 \mathrm{~cm}$ & 60 & $48(80.0)$ & $12(20.0)$ & 0.032 \\
\hline \multicolumn{5}{|c|}{$\begin{array}{l}\text { Histological grade } \\
\text { (differentiation) }\end{array}$} \\
\hline Well & 56 & $52(92.9)$ & $4(7.1)$ & \\
\hline Moderate & 77 & $67(87.0)$ & $10(13.0)$ & 0.188 \\
\hline Poor & 23 & $18(78.3)$ & $5(21.7)$ & \\
\hline \multicolumn{5}{|l|}{ Duke' stage } \\
\hline $\mathrm{A}$ & 48 & $45(93.8)$ & $3(6.2)$ & \\
\hline B & 49 & $43(87.8)$ & $6(12.2)$ & 0.162 \\
\hline $\mathrm{C}$ & 84 & $69(82.1)$ & 15 (17.9) & \\
\hline
\end{tabular}

patients and controls were in agreement with the HardyWeinberg equilibrium. There was no statistically significant association between $M S H 2$ IVS10+12G>A genotypes and susceptibility to sporadic colon cancer, nor with patient survival. Results of the case-control analysis are summarized in Table II.
Table II. Genotypic and allelic frequencies of mutS homolog 2 (MSH2) IVS10+12A>G polymorphism in patients with sporadic colon cancer and controls.

\begin{tabular}{lcccc}
\hline $\begin{array}{l}h M S H 2 \\
\text { IVS10+12A }>\mathrm{G}\end{array}$ & $\begin{array}{c}\text { Controls, } \\
\mathrm{n}(\%)\end{array}$ & $\begin{array}{c}\text { Colon cancer, } \\
\mathrm{n}(\%)\end{array}$ & $\begin{array}{c}\text { OR } \\
(95 \% \mathrm{CI})\end{array}$ & $p$-Value \\
\hline $\mathrm{GG}$ & $105(52.5)$ & $117(58.5)$ & 1 & - \\
$\mathrm{AG}$ & $83(41.5)$ & $68(34.0)$ & $1.36(0.89-2.06)$ & 0.1456 \\
$\mathrm{AA}$ & $12(6.0)$ & $15(7.5)$ & $0.89(0.39-1.99)$ & 0.7789 \\
$\mathrm{G}$ & $293(73.2)$ & $302(75.5)$ & 1 & - \\
$\mathrm{A}$ & $107(26.8)$ & $98(24.5)$ & $1.13(0.82-1.55)$ & 0.4662 \\
\hline
\end{tabular}

MSH2 mRNA expression. In our study, we analyzed the mRNA expression of $M S H 2$ gene in 50 pairs of colon tumors and corresponding normal mucosaI tissue $(15 \mathrm{~cm}$ away from the tumor) by real-time RT-PCR. There was no statistically significant difference in total mRNA expression of the MSH2 gene between the normal mucosal and tumor tissues $(p=0.814)$. In addition, no association was observed between MSH2 mRNA expression in both tumor tissue and corresponding normal mucosal tissue taken from the same patient and tumor differentiation or Dukes' stage of tumors (normal tissue, $p=0.073$ and $p=0.286$, respectively; tumor tissue, $p=0.703$ and $p=0.369$, respectively) (Figure 2a-d). However, a statistically significant correlation of $\mathrm{MSH} 2$ mRNA expression with tumor size was observed for both tumor $(p=0.013)$ and corresponding normal tissue taken from the same patient $(p=0.008)$. The expression of $M S H 2$ mRNA was lower in tumors larger than $5 \mathrm{~cm}$ in diameter than those with smaller size (Figure 2e and f). 
a

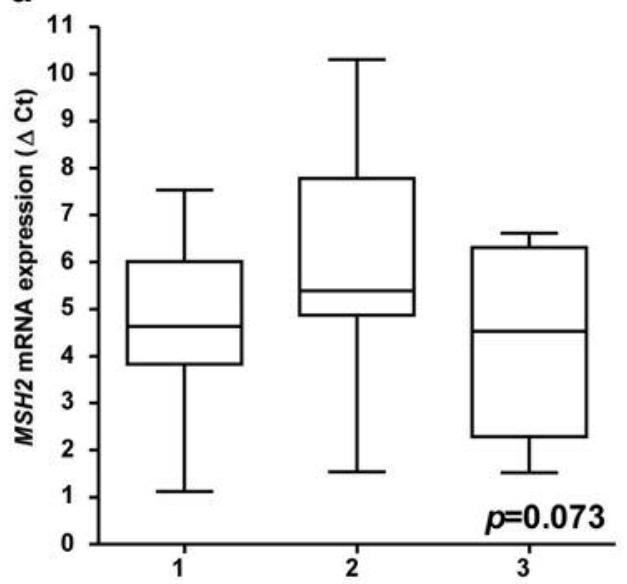

b

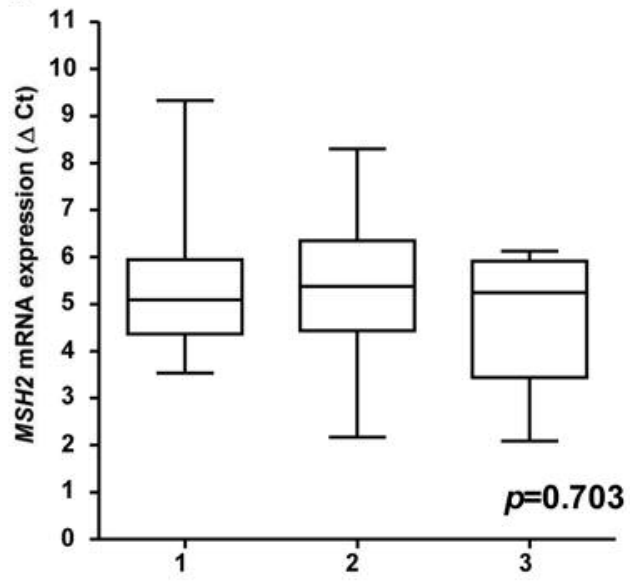

Histological grade (differentiation)

C

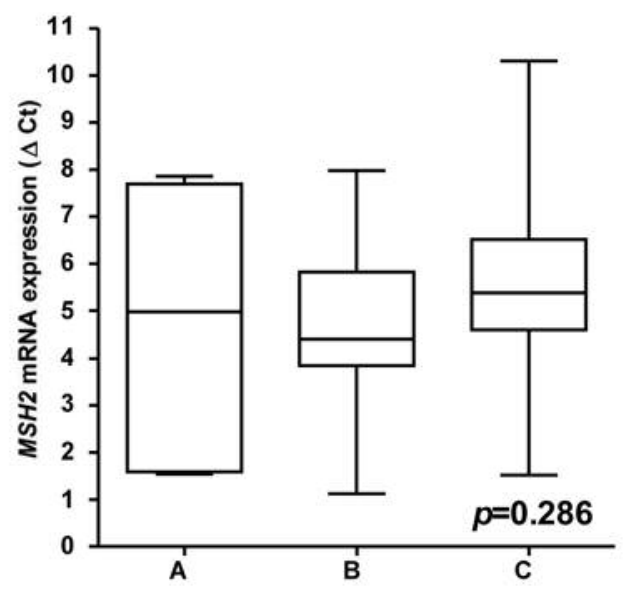

e

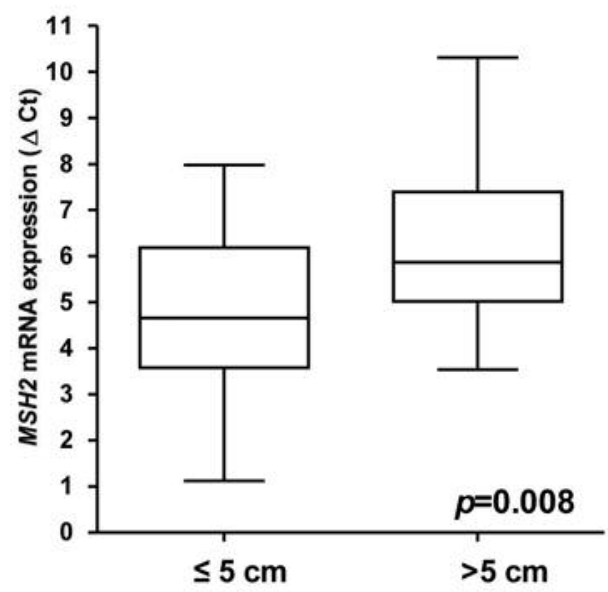

d

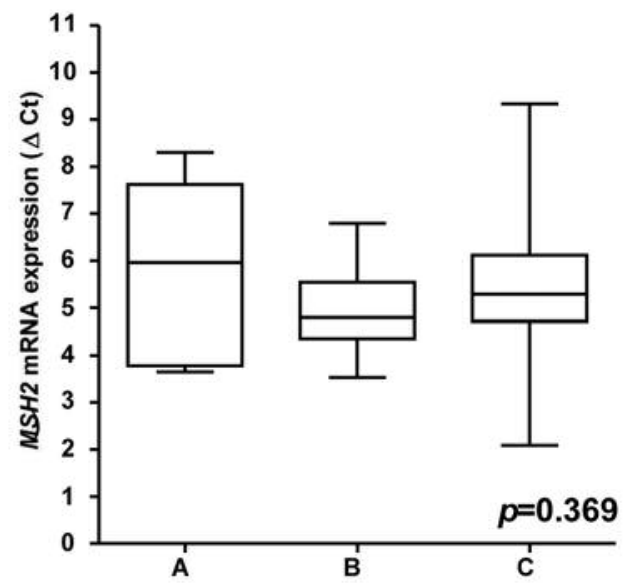

Dukes' stage

$f$

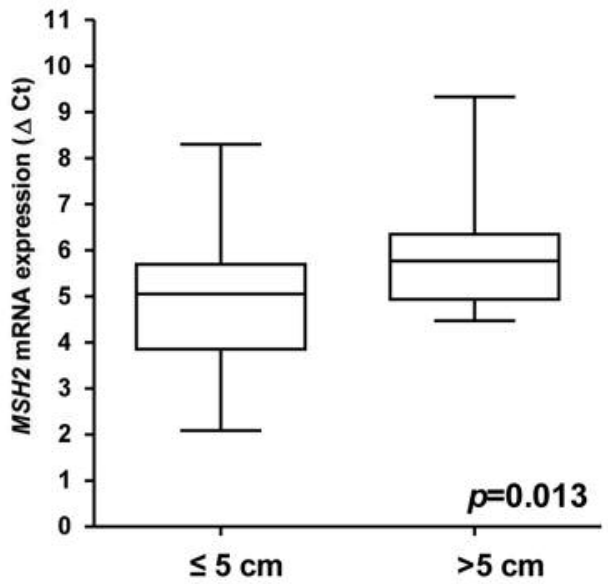

Tumor size

Figure 2. mutS homolog 2 (MSH2) mRNA expression in sporadic colonic tumors and corresponding normal mucosal tissue and clinicopathological features: histological grade ( $A$ and $B)$, Dukes' stage ( $C$ and $D)$ and tumor size ( $E$ and $F)$. $N$, Normal colonic tissue; $T$, tumoral tissue. 
MSH2 protein expression. Expression of MSH2 protein in sporadic colon cancer was analyzed by immunohistochemistry in formalin-fixed paraffin-embedded tissue sections. In normal colon tissue, expression of MSH2 was nuclear. Aberrant MSH2 expression in tumor tissue resulted in either completely MSH2-negative tumor cells or absence of nuclear staining in some tumor cells sometimes accompanied by positive cytoplasmic staining (Figure 3). Normal colon and stromal inflammatory cells served as internal controls. In our study, 57/73 (78.1\%) of tumors stained positively for MSH2. When results of MSH2 immunostaining were examined with respect to clinicopathological characteristics of patients and their tumors, no associations were found (Table III).

Figure 4 presents survival curves of patients stratified according to positive or negative nuclear MSH2 staining in tumor cells. Patients with positive nuclear MSH2 staining lived longer than those with negative nuclear staining, however, this difference was not statistically significant $(p=0.299)$.

\section{Discussion}

Genetic alterations of $\mathrm{MSH} 2$ gene were first described in association with hereditary non-polyposis colorectal cancer, however since then, $\mathrm{MSH} 2$ mutations have been detected in a number of sporadic tumors including colonic, endometrial, stomach, head and neck, and prostate cancer (14). Immunohistochemical studies have shown that the majority of inactivating mutations in the $\mathrm{MSH} 2$ gene lead to the loss of MSH2 protein expression commonly found in tumors with aberrant MMR activity $(15,16)$. On the other hand, contradictory findings of increased $\mathrm{MSH} 2 \mathrm{mRNA}$ or protein expression have been reported in various malignancies, with still unclarified significance $(17,18)$.

In this study, we examined the $M S H 2$ gene status and expression in sporadic colorectal cancer. For $\mathrm{MSH} 2 \mathrm{LOH}$ analysis using two polymorphic markers, total heterozygosity was $90.5 \%$ and $\mathrm{LOH}$ was detected in $13.3 \%$ of heterozygous samples. Our results are in agreement with the findings of Chang et al. who detected MSH2 LOH in $15.7 \%$ (19) and Tsai et al. who detected $\mathrm{MSH} 2 \mathrm{LOH}$ in $16.1 \%$ of analyzed colorectal tumors (20). In our study, there was no correlation between the MSH2 LOH and patient age or sex. In tumors classified as Dukes' C, the frequency of $\mathrm{MSH} 2 \mathrm{LOH}$ was almost three times higher than in tumors classified as Dukes' A, and twice as frequent in Dukes' B compared to Dukes' A tumors, however this difference was not statistically significant. The same progressive trend in $M S H 2 \mathrm{LOH}$ frequency was observed in poorly differentiated tumors compared to well- and moderately differentiated tumors, however, these tendencies did not reach statistical significance. Nevertheless, $M S H 2 \mathrm{LOH}$ was significantly more frequent in tumors larger than $5 \mathrm{~cm}$. Collectively these findings suggest that MSH2 function could be impaired with tumor progression.
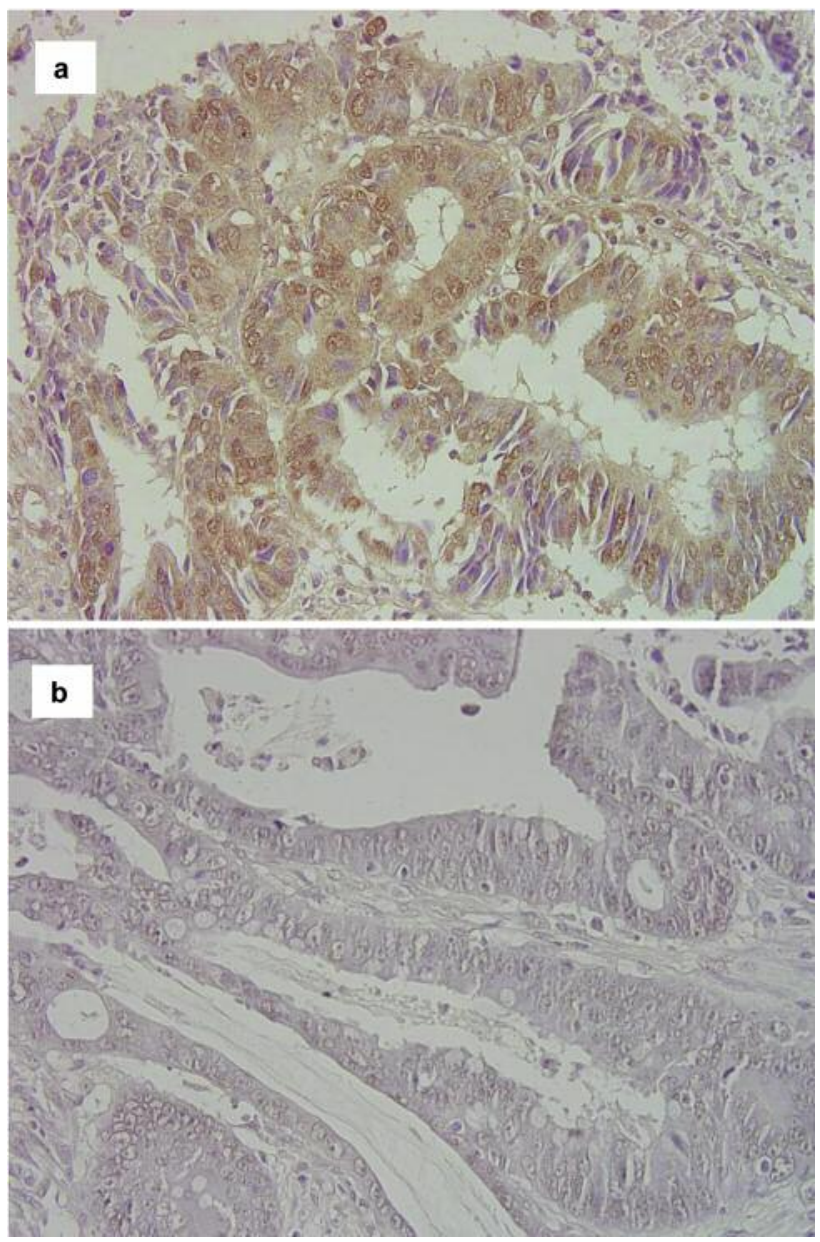

Figure 3. mutS homolog 2 (MSH2) expression in sporadic colonic cancer. A: Tumor sample with positive nuclear and cytoplasmic MSH2 immunostaining. B: Tumor sample negative for MSH2 protein expression. Original magnification $\times 40$.

In addition to mutations and $\mathrm{LOH}$ that result in a complete loss of MSH2 function, in recent years, the role of several polymorphisms affecting the $M S H 2$ expression has been identified. Instead of complete $M S H 2$ functional loss, these polymorphisms may cause interindividual variation in $\mathrm{MSH} 2$ expression level and DNA repair capacity (21). Therefore, it seems that changes in MSH2 expression level might be as important for cancer progression, especially in the tumorigenesis of sporadic cancers, as its complete functional loss. Based on these findings, we decided to analyze $\mathrm{MSH} 2$ mRNA expression in sporadic colonic tumors as well as in the corresponding normal mucosal tissue, as well as the possible influence of $\mathrm{MSH} 2$ IVS10+12A $>\mathrm{G}$ polymorphism on susceptibility to sporadic colonic cancer. No difference in MSH2 mRNA expression in tumor compared with normal tissue was observed in our study. Nevertheless, $M S H 2$ mRNA 
Table III. Clinicopathological features of patients with sporadic colon cancer stratified by mutS homolog 2 (MSH2) protein expression.

\begin{tabular}{|c|c|c|c|c|}
\hline \multirow[b]{2}{*}{ Characteristic } & \multirow[b]{2}{*}{$\begin{array}{l}\text { No. of } \\
\text { cases }\end{array}$} & \multicolumn{2}{|c|}{$M S H 2$ protein expression } & \multirow[b]{2}{*}{$p$-Value } \\
\hline & & $\begin{array}{c}\text { Negative, } \\
\text { n (\%) }\end{array}$ & $\begin{array}{l}\text { Positive, } \\
\text { n (\%) }\end{array}$ & \\
\hline \multicolumn{5}{|l|}{ Age } \\
\hline$<70$ years & 48 & $11(22.9)$ & $37(77.1)$ & \multirow[t]{2}{*}{0.775} \\
\hline$\geq 70$ years & 25 & $5(20.0)$ & $20(80.0)$ & \\
\hline \multicolumn{5}{|l|}{ Gender } \\
\hline Male & 39 & $9(23.1)$ & $30(76.9)$ & \multirow[t]{2}{*}{0.797} \\
\hline Female & 34 & $7(20.6)$ & $27(79.4)$ & \\
\hline \multicolumn{5}{|l|}{ Tumor size } \\
\hline$\leq 5 \mathrm{~cm}$ & 36 & 7 (19.4) & 29 (80.6) & \multirow{3}{*}{0.614} \\
\hline$>5 \mathrm{~cm}$ & 37 & $9(24.3)$ & $28(75.7)$ & \\
\hline \multicolumn{4}{|c|}{$\begin{array}{l}\text { Histological grade } \\
\text { (differentiation) }\end{array}$} & \\
\hline Well & 28 & $6(21.4)$ & $22(78.6)$ & \multirow{3}{*}{0.181} \\
\hline Moderate & 29 & $9(31.0)$ & $20(69.0)$ & \\
\hline Poor & 15 & $1(6.7)$ & $14(93.3)$ & \\
\hline \multicolumn{5}{|l|}{ Dukes'stage } \\
\hline A & 10 & $2(20.0)$ & $8(80.0)$ & \multirow{3}{*}{0.986} \\
\hline B & 32 & 7 (21.9) & $25(78.1)$ & \\
\hline $\mathrm{C}$ & 31 & $7(22.6)$ & $24(77.4)$ & \\
\hline
\end{tabular}

expression was significantly lower in tumors larger than $5 \mathrm{~cm}$ in diameter. These findings support our observation that these tumors had higher frequency of $\mathrm{MSH} 2 \mathrm{LOH}$.

Langner et al. observed the loss of MSH2 mRNA expression in about $40 \%$ of patients with sporadic colorectal cancer (22). This finding differs from ours probably due to the less sensitive method used for mRNA quantification in their study (semi-quantitative PCR). Furthermore, they did not find any significant correlation between the loss of the $\mathrm{MSH} 2$ gene expression and clinicopathological parameters such as Dukes' stage, histological grade or lymph node metastasis. However, they did not examine mRNA expression in relation to the tumor size, or the $M S H 2$ mRNA expression in normal mucosal tissue.

The presence of genetic changes in the matched normal mucosa of patients with sporadic colonic cancer has recently been recognized. For instance, Sidelnikov et al. found that lower MSH2 protein expression in the normal colonic mucosa may be associated with increased risk of sporadic colorectal adenoma (23). Furthermore, since $M S H 2$ expression is likely to indicate the functional level of the DNA MMR mechanism, Sidelnikov et al. suggested that $\mathrm{MSH} 2$ protein expression in normal colorectal mucosa might be a promising candidate biomarker for colorectal cancer (22).

Therefore, in an effort to examine the role of $M S H 2$ in tumorigenesis of sporadic colorectal cancer in addition to mRNA expression analysis in tumors, we analyzed that in

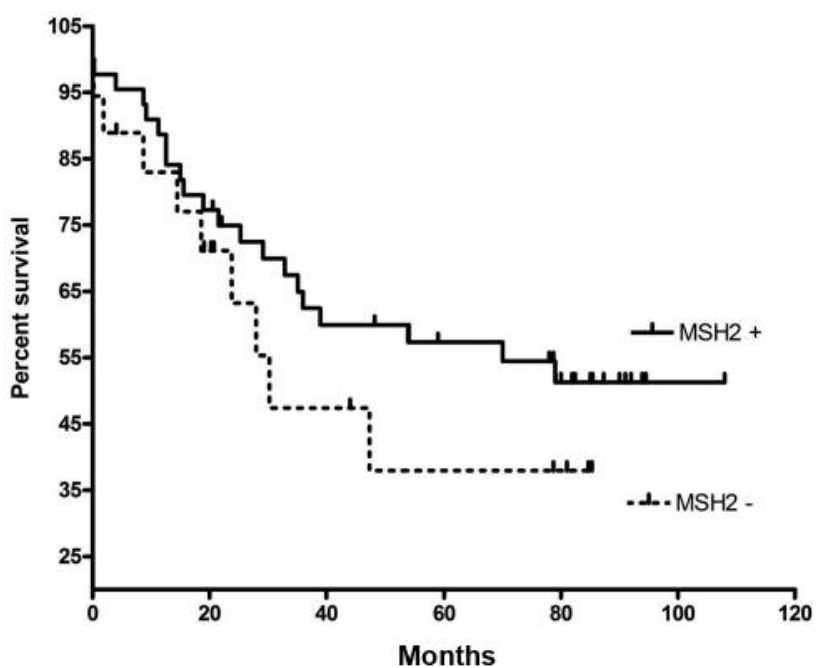

Figure 4. Survival curves of patients according to nuclear mutS homolog 2 (MSH2) staining status in tumor cells.

corresponding normal mucosal tissue. We did not find any correlation between the mRNA expression in normal mucosal tissue in relation to clinicopathological features of patients and their tumors except for the tumor size. Interestingly, $\mathrm{MSH} 2$ mRNA expression in normal mucosal tissue followed the same expression pattern as that in the corresponding tumors, and these findings were statistically significant.

In our study, we did not find any correlation between MSH2 protein expression and clinicopathological characteristics of patients and their tumors. These findings are in accordance with findings of previous study by Amira et al. (24). Patients with tumors nuclear MSH2 staining had longer survival times compared to patients with $M S H 2$ nuclearnegative staining; nevertheless, this difference was not statistically significant. These findings might suggest that nuclear MSH2 staining is an indicator of better prognosis.

Although polymorphisms in DNA repair genes with possible influence on MMR function have been known for some time, there are still relatively few studies examining their influence on susceptibility to cancer. In particular, although the functional significance of the IVS10+12A>G polymorphism still remains to be elucidated, it has been proposed that it may influence alternative splicing of $\mathrm{MSH} 2$ resulting in interindividual variation in the expression levels of the MSH2 splicing variants with different DNA repair capacity (25). In the study of Jung et al., the presence of at least one IVS10+12G allele was associated with a significantly reduced risk of lung adenocarcinoma as compared with the IVS10+12AA genotype (21). In addition, Kim et al. found that IVS $10+12 \mathrm{~A}>\mathrm{G}$ polymorphism was an independent prognostic marker for patients with colorectal 
cancer (10). In our study we did not find an association between the $M S H 2$ IVS10+12A $>\mathrm{G}$ polymorphism and susceptibility to sporadic colon cancer.

Based on our findings, we conclude that $M S H 2$ expression is altered in sporadic colonic tumors demonstrating its role in colorectal tumorigenesis without the hereditary component.

\section{Acknowledgements}

This work was supported by Grant number 098-0982464-2508, from the Ministry of Science and Technology, Republic of Croatia and grant number IP-2016-06-1430, from Croatian Science Foundation.

\section{References}

1 Fearon ER: Molecular genetics of colorectal cancer. Annu Rev Pathol Mech Dis 6: 479-507, 2011.

2 Morán A, Ortega P, de Juan C, Fernández-Marcelo T, Frías C, Sánchez-Pernaute A, Torres AJ, Díaz-Rubio E, Iniesta P and Benito M: Differential colorectal carcinogenesis: Molecular basis and clinical relevance. World J Gastrointest Oncol 2: 151-158, 2010.

3 Fearon ER and Vogelstein B: A genetic model for colorectal tumorigenesis. Cell 61: 759-767, 1990.

4 Imai $\mathrm{K}$ and Yamamoto $\mathrm{H}$ : Carcinogenesis and microsatellite instability: the interrelationship between genetics and epigenetics. Carcinogenesis 29: 673-680, 2008.

5 Söreide K, Janssen EA, Söiland H, Körner H and Baak JP: Microsatellite instability in colorectal cancer. Br J Surg 93: 395406, 2006

6 Preston BD, Albertson TM and Herr AJ: DNA replication fidelity and cancer. Semin Cancer Biol 20: 281-293, 2010.

7 Hou Y, Gao F, Wang Q, Zhao J, Flagg T, Zhang Y and Deng X: $\mathrm{Bcl} 2$ impedes DNA mismatch repair by directly regulating the hMSH2-6 heterodimeric complex. J Biol Chem 282: 9279-9287, 2007.

8 Claij $\mathrm{N}$ and Riele HT: Methylation tolerance in mismatch repair proficient cells with low MSH2 protein level. Oncogene 21: 2873-2879, 2002.

9 Jensen L, Danenberg K, Danenberg P and Jakobsen A: Predicive value of MSH2 gene expression in colorectal tumours based on mismatch repair deficiency. Colorectal Dis 10: 490-497, 2008.

10 Kim JG, Chae YS, Sohn SK, Moon JH, Kang BW, Park JY, Jeon SW, Lee MH, Lim KH, Choi GS and Jun SH: IVS10+12A>G polymorphism in $h M S H 2$ gene associated with prognosis for patients with colorectal cancer. Ann Oncol 1: 525-529, 2010.

11 Spaventi R, Pecur L, Pavelic K, Pavelic ZP, Spaventi S and Stambrook PJ: Human tumor bank in Croatia: a possible model for a small bank as a part of future European tumor bank network. Eur J Cancer 30A: 419, 1994.

12 Boland CR, Thibodeau SN, Hamilton SR, Sidransky D, Eshleman JR, Burt RW, Meltzer SJ, Rodriguez-Bigas MA, Fodde R, Ranzani GN and Srivastava S: A National Cancer Institute Workshop on Microsatellite Instability for cancer detection and familial predisposition: development of international criteria for the determination of microsatellite instability in colorectal cancer. Cancer Res 58: 5248-5257, 1998.
13 Cacev T, Radosevic S, Spaventi R, Pavelic K and Kapitanovic S: NF1 gene loss of heterozygosity and expression analysis in sporadic colon cancer Gut 54: 1129-1135, 2005.

14 Seifert M and Reichrath J: The role of the human DNA mismatch repair gene $h M S H 2$ in DNA repair, cell cycle control and apoptosis: implications for pathogenesis, progression and therapy of cancer. J Mol Histol 37: 301-307, 2006.

15 Shia J, Ellism NA and Klimstra D: The utility of immunohistochemical detection of DNA mismatch repair gene proteins. Virchows Arch 445: 431-441, 2004.

16 Lee KH, Lee JS, Nam JH, Choi C, Lee MC, Park CS, Juhng SW and Lee JH: Promoter methylation status of $h M L H 1, h M S H 2$, and MGMT genes in colorectal cancer associated with adenomacarcinoma sequence. Langenbecks Arch Surg 396: 1017-1026, 2011.

17 Leach FS, Hsieh JT, Molberg K, Saboorian MH, McConnell JD and Sagalowsky AI: Expression of the human mismatch repair gene $h M S H 2$ : a potential marker for urothelial malignancy. Cancer 88: 2333-2341, 2000.

$18 \mathrm{Li} \mathrm{M}$, Liu L, Wang Z, Wang L, Liu Z, Xu G and Lu S: Overexpression of hMSH2 and hMLH1 protein in certain gastric cancers and their surrounding mucosae. Oncol Rep 19: 401-406, 2008.

19 Chang S-C, Lin J-K, Lin T-C and Liang W-Y: Loss of heterozygosity: An independent prognostic factor of colorectal cancer. World J Gastroenterol 11: 778-784, 2005.

20 Tsai MH, Fang WH, Lin SW, Yen SJ, Chou SJ and Yang YC: Mitochondrial genomic instability in colorectal cancer: no correlation to nuclear microsatellite instability and allelic deletion of $h M S H 2, h M L H 1$, and $p 53$ genes, but prediction of better survival for Dukes' stage C disease. Ann Surg Oncol 16: 29182925, 2009.

21 Jung CY, Choi JE, Park JM, Chae MH, Kang HG, Kim KM, Lee SJ, Lee WK, Kam S, Cha SI, Kim CH, Han SB, Jung TH, Jeon SH and Park JY: Polymorphisms in the $h M S H 2$ gene and the risk of primary lung cancer. Cancer Epidemiol Biomarkers Prev 15: 762-768, 2006.

22 Langner E, Przybylowska K, Trzcinski R, Mik M, Galbfach P, Smolarz B, Romanowicz-Makowska H, Smigileski J, Kulig A and Dziki A: Loss of $h M S H 2$ gene expression correlates with improved survival in patients with sporadic colorectal cancer. $\mathrm{J}$ Genet 89: 101-104, 2010.

23 Sidelnikov E, Bostick RM, Flanders WD, Long Q and Seabrook ME: Colorectal mucosal expression of MSH2 as a potential biomarker of risk for colorectal neoplasms. Cancer Epidemiol Biomarkers Prev 18: 2965-2973, 2009.

24 Amira AT, Mouna T, Ahlem B, Raoudha A, Majid BH, Amel H, Rachida $\mathrm{Z}$ and Nadia K: Immunohistochemical expression pattern of MMR protein can specifically identify patients with colorectal cancer microsatellite instability. Tumour Biol 35: 62836291, 2014.

25 Farrington SM, Lin-Goerke J, Ling J, Wang Y, Burczak JD, Robbins DJ and Dunlop MG: Systematic analysis of hMSH2 and hMLH1 in young colon cancer patients and controls. Am J Hum Genet 63: 749-759, 1998.

Received February 14, 2018

Revised March 5, 2018

Accepted March 6, 2018 